\title{
Shrinkage Performance of Fly Ash Alkali-activated Cement Based Binder Mortars
}

\author{
M. Kheradmand*, Z. Abdollahnejad**, and F. Pacheco-Torgal*** \\ Received October 11, 2016/Revised February 2, 2017/Accepted June 8, 2017/Published Online
}

\begin{abstract}
Some authors reported that Alkali-activated Cement Based Binder (AACB) mortars can have much higher drying shrinkage than Portland cement based composites. Its worth remember that shrinkage performance is a very important property for reinforced concrete composites just because a high shrinkage performance is associated to cracking tendency that leads to future durability problems. Usually shrinkage is assessed under unrestrained conditions. However, the use of a restrained ellipse ring test is especially interesting for materials that will be used in restrained conditions like repair mortars. This paper provides results on restrained and unrestrained shrinkage performance of fly ash AACB mortars. The restrained shrinkage was assessed with an elliptical ring that provides a faster and more reliable assessment of the cracking potential than circular rings. The results show that the mixtures with lower sodium silicate content are associated to a lower unrestrained shrinkage. Mixtures with lower sodium silicate content showed reduced average crack width under restrained conditions. The results also show that the reduction of sodium silicate content delays the appearance of cracks and is also associated to lower crack width. The use of AACB mortars in restrained conditions requires the use of a reduced sodium silicate content or else the use of fibres to prevent crack appearance.
\end{abstract}

Keywords: waste reuse, AACB mortars, fly ash, capillary water absorption, shrinkage

\section{Introduction}

AACB are OPC alternative materials produced though the reaction of an aluminosilicate powder (precursor) with an alkaline activator, usually composed by hydroxide, silicate, carbonate or sulfate leading to the formation an amorphous aluminosilicate gel and secondary nano crystalline zeolite-like structures (van Deventer et al., 2010, 2012; Pacheco-Torgal et al., 2014; Provis, 2014).

These materials have a particular ability for the reuse of several types of waste (Payá et al., 2014; Chindaprasirt and Cao, 2014; Bernal et al., 2016). This is an important feature especially in the European context of a circular economy and zero waste target (COM, 2014) that may lead to an overall savings potential of several hundred billion euro per year for the European industry and can also create almost two hundred thousand direct jobs in the EU by 2030.

Some wastes like fly ash deserve an especial attention because they are generated in a very high amount and have a very low reuse rate. The reuse rate of fly ash in USA is around 50\% meaning that million tons of fly ash are not reused annually (ACAA, 2016). Other recent works confirm the importance of further studies regarding the development of AACB based on fly ash precursors (Zhuang et al., 2016).
Shrinkage performance is a very important property for reinforced concrete composites just because a high shrinkage performance is associated to cracking tendency that leads to future durability problems. Some authors (Collins and Sanjayan, 1999, 2000) reported that $\mathrm{AACB}$ composites can have much higher autogenous shrinkage than Portland cement based composites that could be explained by the fact that AACB composites showed a much higher mesopores content ( $82 \%$ versus $36 \%$ ). Recent investigations confirmed this pore related explanation (Mobili et al., 2016). However, AACB shrinkage is also dependent on the curing conditions being that curing with temperature is associated with a lower autogenous shrinkage (Wallah and Hardjito, 2014). Recent investigations showed that slag-fly ash AACB composites with a higher content of slag are associated with higher drying shrinkage (Gao et al., 2016). This was also confirmed by Ye and Radlinska (2016) who suggested that shrinkage may be attributed to the structural incorporation of alkali cations in C-A-S-H, which reduces the stacking regularity of C-A-S-H layers and make the C-A-S-H easier to collapse and redistribute upon drying (Fig. 1).

Usually shrinkage performance is assessed through unrestrained shrinkage testing. Assessment of shrinkage using circular or ellipse restrained ring test is especially interest for materials that will be used in restrained conditions like repair mortars (Kristiawan, 2012; Khan, 2013; Beushausen and Chilwesa, 2013). Some

\footnotetext{
*Posdoc Researcher, C-TAC Research Centre, University of Minho, Guimarães, Portugal (E-mail: mohammadkheradmand@hotmail.com)

**Posdoc Researcher, C-TAC Research Centre, University of Minho, Guimarães, Portugal (E-mail: tolumahvash@gmail.com)

***Principal Investigator, C-TAC Research Centre, University of Minho, Guimarães, Portugal; SHRC, University of Sungkyunkwan, Suwon 03063, Korea (Corresponding Author, E-mail: torgal@civil.uminho.pt)
} 


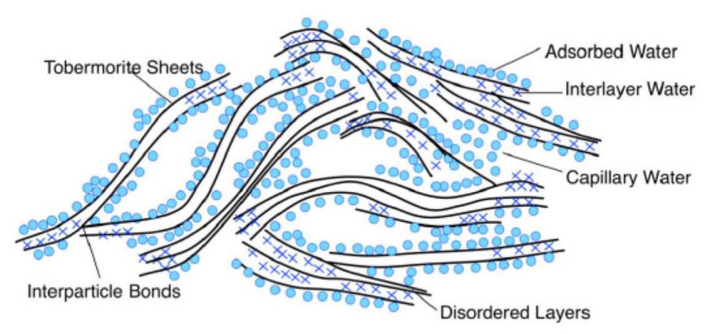

(a)

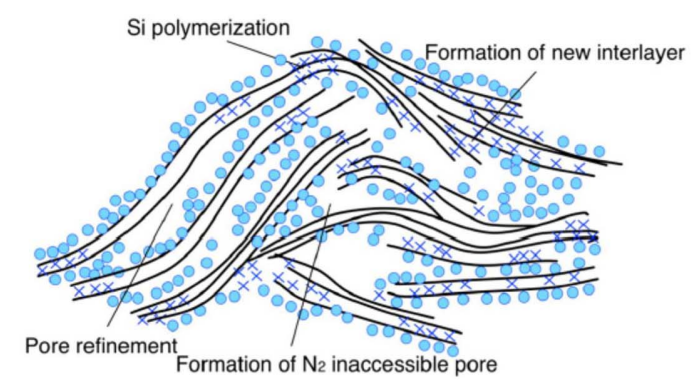

(b)

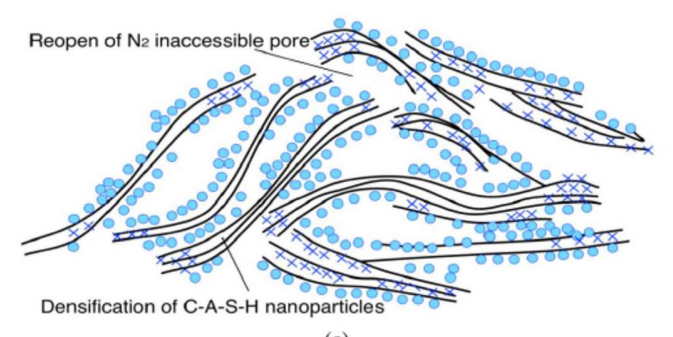

(c)

Fig. 1. Illustration of Nanostructure Changes of C-A-S-H During Drying: (a) Before Drying, CA-S-H Comprises of Primarily Amorphous Tobermorite-like Sheets, (b) After drying, CAS-H Redistributes and Organizes; Rendering Pore Refinement, Silicate Polymerization, and New Interlayer Formation, (c) Dried at low RH ( 11\%RH), C-A-S-H Densifies and Loses Some Interlayer Water (Ye and Radlinska, 2016)

authors (Collins and Sanjayan, 2000) compared AACB and OPC concrete performance under restrained ring test reporting that the former cracked after only 1 week of curing, while the latter cracked only after 5 months. Ma and Ye (2015) recently published results comparing unrestrained and restrained shrinkage performance of fly ash AACB pastes stating that no cracks were detected. This paper provides results on restrained and unrestrained shrinkage performance of fly ash AACB mortars.

\section{Experimental Program}

\subsection{Materials}

The raw materials used for the preparation of the AACB mortars were fly ash, calcium hydroxide, kaolin, cement type I $42.5 \mathrm{R}$, sand, sodium silicate, sodium hydroxide and superplastisizer. Solid sodium hydroxide obtained from commercially available product of ERCROS, S.A., Spain, was used to prepare a 12M $\mathrm{NaOH}$ solution. Distilled water was used to dissolve the sodium
Table 1. Chemical Composition of Major Oxides

\begin{tabular}{c|c|c|c|c|c|c|c|c}
\hline \multirow{2}{*}{ Material } & \multicolumn{7}{|c}{ Oxides (wt.\%) } \\
\cline { 2 - 9 } & $\mathrm{SiO}_{2}$ & $\mathrm{Al}_{2} \mathrm{O}_{3}$ & $\mathrm{Fe}_{2} \mathrm{O}_{3}$ & $\mathrm{CaO}$ & $\mathrm{MgO}$ & $\mathrm{Na}_{2} \mathrm{O}$ & $\mathrm{K}_{2} \mathrm{O}$ & $\mathrm{TiO}_{2}$ \\
\hline Fly Ash & 60.81 & 22.68 & 7.64 & 1.01 & 2.24 & 1.45 & 2.7 & 1.46 \\
\hline
\end{tabular}

hydroxide flakes to avoid the effect of unknown contaminates in the mixing water. The $\mathrm{NaOH}$ mix was made one day prior to use in order to have a homogenous solution at the time of mortar preparation. The chemical composition of the sodium hydroxide was composed of $25 \% \mathrm{Na}_{2} \mathrm{O}$ and $75 \% \mathrm{H}_{2} \mathrm{O}$. The sodium silicate was supplied by MARCANDE, Portugal. The chemical composition of the sodium silicate was of $13.5 \% \mathrm{Na}_{2} \mathrm{O}, 58.7 \% \mathrm{SiO}_{2}$ and $45.2 \% \mathrm{H}_{2} \mathrm{O}$. The fly ash was obtained from the PEGO Thermal Power Plant in Portugal and it was classified as class F according to ASTM-C618 (2015) standard. The chemical composition of the fly ash selected for this study is presented in Table 1 . The particle size distribution of the fly ash was varied from $2 \mu \mathrm{m}$ to $59 \mu \mathrm{m}$. Fly ash was partially replaced by Portland cement type I class 42.5R from SECIL, Portugal and also by calcium hydroxide from LUSICAL H100. In term of chemical components, the cement contains $63.3 \% \mathrm{CaO}, 21.4 \% \mathrm{SiO}_{2}, 4.0 \% \mathrm{Fe}_{2} \mathrm{O}, 3.3 \% \mathrm{Al}_{2} \mathrm{O}_{3}$, $2.4 \% \mathrm{MgO}$ and other components. The calcium hydroxide used in this study contains more that $99 \% \mathrm{CaO}$. The sand was used as inert filler and was provided by MIBAL, Minas de Barqueiros, S.A. Portugal. Prior to its use it was sieved in order to remove dusts particles. The sieves used in this operation had a $4.75 \mathrm{~mm}$ and a $0.6 \mathrm{~mm}$ mesh size.The detailed grain size distribution of the aggregates presented in Fig. 3. The superplastisizer was supplied by BASF. It's a polycrylate from Acronal series, with a density of $1050 \mathrm{~kg} . \mathrm{m}^{3}$.

\subsection{Production of AACB Mortar Specimens}

A sodium hydroxide solution (12M) was mixed with sodium silicate to dissolve the silica and alumina of the fly ash particles, resulting a homogenized gel lasting $1 \mathrm{~min}$; next, all the solid materials were mixed by using standard mixer operating at the following speed I ( $65 \mathrm{rpm})$ for $3 \mathrm{~min}$. After the addition of the alkaline activator the mixer was operated during $1 \mathrm{~min}$ with speed I (65 rpm) and plus another 1 min with speed II $(90 \mathrm{rpm})$. After the casting the unrestrained shrinkage specimens were cured at laboratory conditions with temperature about $25^{\circ} \mathrm{C}$ and $65 \%$ of relative humidity. After $\approx 4 \mathrm{hr}$ the specimens were demoulded and kept sealed with the plastic wrap and then left in the same curing conditions until the date of testing. Concerning restrained shrinkage, the AACB mortar was transferred to an elliptical mould. Then, this mould was placed on the vibration table for 2 min. The specimens were kept sealed by using plastic wrap and they were cured at laboratory conditions with temperature $20 \pm 3^{\circ} \mathrm{C}$ and $70 \% \pm 10 \% \mathrm{HR}$. After $24 \mathrm{hr}$ the specimen the outer elliptical ring was removed and then left in the same curing conditions. The specimens in the elliptical mould were monitored during 14days in order to detected crack formation on the surface of the specimens. 


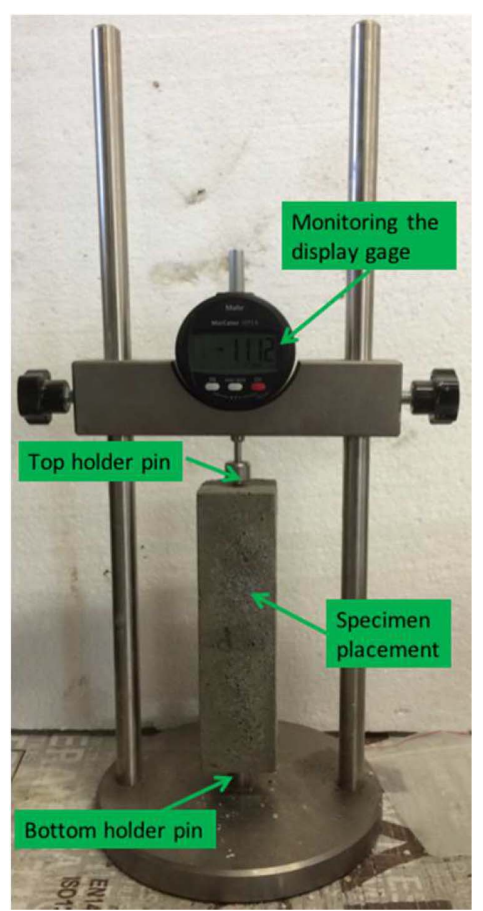

Fig. 2. Type of Used Digital Micrometer Apparatus for Measurement of Length Changes

\subsection{Test Procedures}

The following tests have been carried out: unrestrained shrinkage, restrained shrinkage, modulus of elasticity and capillary water absorption. A total of 6 mixtures were tested under both shrinkage tests. This included 4 representative mixtures made with fly ash $(90 \% \mathrm{FA})$, calcium hydroxide $(10 \% \mathrm{CH})$ and a sodium hydroxide activator (12M) with two activator/binder ratios (0.8 and 1.0), with two sodium silicate to sodium hydroxide mass ratios $(2.0$ and 2.5). The composition of the AACB mixtures can be found in Table 2.

\subsubsection{Capillary Water Absorption}

The capillary water absorption was performed according to EN 1015-18 standard. The specimens had the following dimensions $40 \mathrm{~mm} \times 40 \mathrm{~mm} \times 80 \mathrm{~mm}$. The surface the specimens were coated with silicon in order to assure the water can be absorbed from one surface of the specimens that is soaked in water. The quantification of absorbed water was performed by conducting weightings of the specimens through several segment intervals which started at $0 \mathrm{~min}, 5 \mathrm{~min}, 10 \mathrm{~min}, 20 \mathrm{~min}, 30 \mathrm{~min}, 60 \mathrm{~min}$, $90 \mathrm{~min}, 120 \mathrm{~min}, 180 \mathrm{~min}, 240 \mathrm{~min}, 300 \mathrm{~min}, 360 \mathrm{~min}, 1440 \mathrm{~min}$ and $2880 \mathrm{~min}$. However, it should be mentioned that, in order to assess the evolution of the water absorption towards weight stabilization, periodic measurements were performed for about 4days. The capillary absorption coefficient was determined according to the following (Eq. (2)):

$$
C=\frac{M 2-M 1}{\sqrt{t f-t i}}
$$

In which, $C$ is the capillary water absorption coeffiecnt $(\mathrm{kg} /$ $\left.\left(\mathrm{m}^{2} \cdot \mathrm{min}^{0.5}\right)\right) ; M 2$ is the weight if the specimen in contact with water at the instant $10 \mathrm{~min}\left(\mathrm{~kg} / \mathrm{m}^{2}\right) ; M 1$ is the weight if the specimen in contact with water at the instant of $90 \mathrm{~min}\left(\mathrm{~kg} / \mathrm{m}^{2}\right)$; tf is the final time, instant of $90 \mathrm{~min}(\mathrm{~min})$; and $t i$ is the initial time, instant of $10 \mathrm{~min}$ (min).

\subsubsection{Modulus of Elasticity}

The modulus of elasticity test was based on cylindrical specimens (88 $\mathrm{mm}$ in diameter and $170 \mathrm{~mm}$ in length). $24 \mathrm{hr}$ prior to all testing, cylinders were capped using a stabilizer compound which provided a smooth surface for the platen to contact and reduced variability between compression specimens. The test was done according to the European standard EN 12390-13. Mortar cylinders from each mixture were tested under $100 \mathrm{KN}$ capacity testing frame. Computer software controlled the load rate and collected data for the applied force. Three Linear Variable Differential Transformer (LVDT) attached to a compressometer and wired to the data acquisition system and computer software as a standard strain gauges. Two rings were considered to be placed at the height of one-third and two-third of global height of the cylinder which the axis distances between the rings were considered fixed of $60 \mathrm{~mm}$ through all the tests. In fact, three LVDTs are rigidity attached upon top ring and are free to rotate on the horizontal surface of the bottom ring. Using loading cycled upon $40 \%$ of the ultimate stress, to obtain the equation of the straight line in the elastic zone for each specimen. The slope of this line in the static modulus of elasticity. Data for load and displacement was acquired automatically by the computer software, and the modulus of elasticity of each specimen was

Table 2. Mixture Composition of AACB Mortars

\begin{tabular}{|c|c|c|c|c|c|c|c|c|c|}
\hline \multirow{2}{*}{ Sample name } & \multicolumn{9}{|c|}{ Materials $\left(\mathrm{kg} / \mathrm{m}^{3}\right)^{*}$} \\
\hline & $\mathrm{PC}$ & MK & FA & $\mathrm{CH}$ & SA & SS & SH & SP & WT \\
\hline 90FA_10CH_12M_2.5S/H_0.8A/B & 0 & 0 & 438.5 & 48,7 & 1461.5 & 278 & 111.7 & 0 & 0 \\
\hline 90FA_10PC_12M_2.5S/H_0.8A/B & 49 & 0 & 441.5 & 0 & 1471.3 & 280 & 112.5 & 0 & 0 \\
\hline 90FA_10CH_12M_2.5S/H_1.0A/B & 0 & 0 & 415.8 & 46.2 & 1385.9 & 330 & 132.4 & 0 & 0 \\
\hline 90FA_10CH_12M_2.0S/H_0.8A/B & 0 & 0 & 435 & 48.3 & 1449.5 & 257.7 & 128.8 & 0 & 0 \\
\hline 90FA_10PC_12M_2.0S/H_0.8A/B & 48.6 & 0 & 437.7 & 0 & 1459.2 & 259.4 & 129.7 & 0 & 0 \\
\hline 90FA_10CH_12M_2.0S/H_1.0A/B & 0 & 0 & 411.2 & 45.8 & 1372.3 & 304.9 & 152.5 & 0 & 0 \\
\hline
\end{tabular}

*PC: stands for the Portland cement; MK: stands for the metakaolin; FA: stands for the fly ash; CH: stands for the calcium hydroxide; SA: stands for sand; SS: stands for sodium silicate; SH: stands for the sodium hydroxide; SP: stands for superplastisizer; WT: stands for the water. 
calculated as the average of the three slopes of the stress-strain curves.

\subsubsection{Unrestrained Shrinkage}

The unrestrained shrinkage test used specimens with dimensions of $40 \mathrm{~mm} \times 40 \mathrm{~mm} \times 160 \mathrm{~mm}$. The procedure of the length change assessment followed recommendation of ASTM C49000 standard. The length changes measurements started at the second day from casting and continued up to 28 days. The specimens were cured in a control room condition at $20 \pm 3^{\circ} \mathrm{C}$ and $70 \% \pm 10 \%$ relative humidity. In order to calculate the length change, each specimen was placed into the apparatus model Mahr-MarCator 1075R (Fig. 2). Then the four sides of the specimens were monitored by rotating the specimen slowly in the measuring apparatus while the reading is taken and the mean value was considered. The length change of the specimens were reported when compared with the reference specimen with a digital micrometer in microstrain. A dimensionless parameter $\mathrm{L}$ has been introduced to evaluate the effect of controlled curing on the mass loss percentage (Eq. (1)):

$$
L=\frac{\Delta w}{w_{o}}
$$

Where $\Delta w$ is the increment of weight loss and $w_{0}$ is the initial weight of the specimen.

\subsubsection{Restrained Shrinkage}

Restrained shrinkage tests were conducted using an elliptical ring test. Just because several authors (Zhou et al., 2014; Dong et al., 2014) have already demonstrated the advantages of using elliptical rings over circular ones in faster and more reliable assessment of cracking potential of cementitious composites. Also contrary to circular ring in which a crack may initiate anywhere, for an elliptical ring specimen, it tends to be at a determinable position, reducing the resources needed for detecting crack initiation/propagation in the ring test (Dong et al., 2016). The dimensions of the elliptical ring test were the same of the one

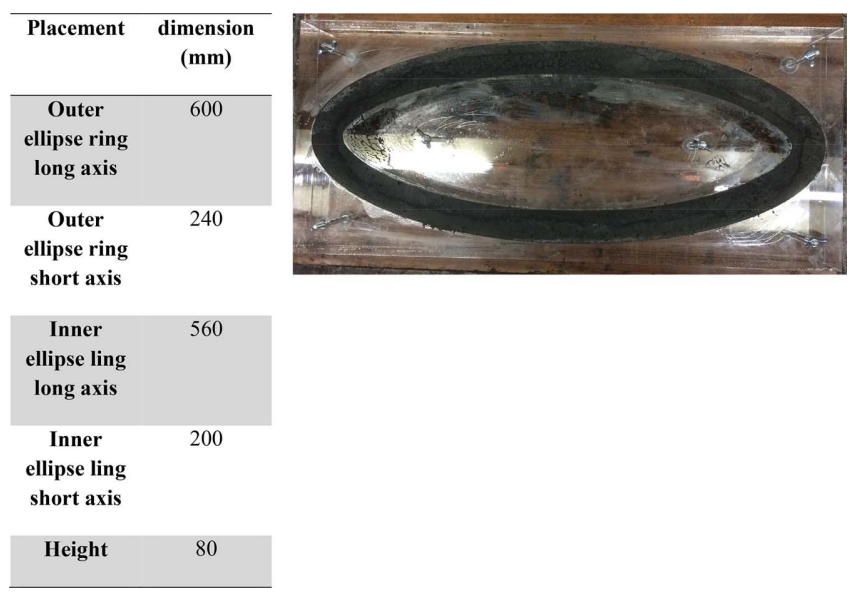

Fig. 3. Ellipse Ring Test Setup (including a table with dimensions of the ellipse sample) used recently by Ma and Ye (2015). Its dimensions are shown in Fig. 3).

\section{Results and Discussion}

\subsection{Capillary Water Absorption}

Capillary water absorption coefficients as well as capillary water absorption with time are shown in Fig. 4 and Fig. 5. The capillary water absorption coefficients for AACB mortars range from $\approx 0.23 \mathrm{~kg} / \mathrm{m}^{2} \min ^{0.5}$ to $0.51 \mathrm{~kg} / \mathrm{m}^{2} \min ^{0.5}$. This values are within the interval $\left(0.1-0.9 \mathrm{~kg} / \mathrm{m}^{2}\right)$ already reported by other authors that studied alkali-activated binders (Pinto, 2004; Pacheco-Torgal et al., 2008). A minor reduction on the capillary water absorption coefficient is noticed when the sodium silicate amount is reduced. This finding was already reported by other authors (Borges et al., 2016). For the same mixture the reduction of the activator/binder from 1 to 0.8 is responsible for a reduction on the capillary water absorption coefficient of around $50 \%$. The higher value was reported for the mixture with $90 \%$ FA plus $10 \%$ $\mathrm{CH}$ with the higher content of sodium silicate and a ratio activator/ binder of 1.0. The replacement of $10 \%$ fly ash by Portland cement or by $10 \%$ calcium hydroxide show no relevant differences concerning the capillary water absorption.

\subsection{Modulus of Elasticity}

The results of the modulus of elasticity are shown in Table 3. The reduction of activator/binder ratio from 1.0 to 0.8 leads to high increase of the modulus of elasticity in the AACB mortars. As to the influence of OPC addition the results show that the

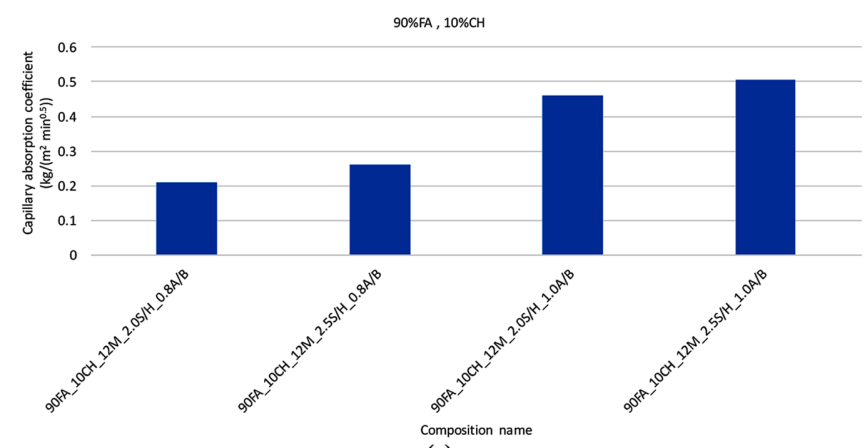

(a)

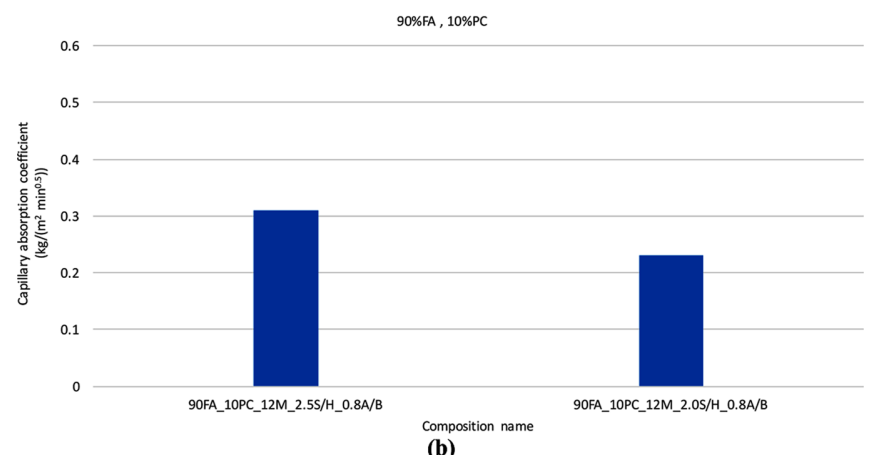

Fig. 4. Capillary Water Absorption Coefficient: (a) $90 \% \mathrm{FA}, 10 \% \mathrm{CH}$, (b) $90 \% \mathrm{FA}, 10 \% \mathrm{PC}$ 


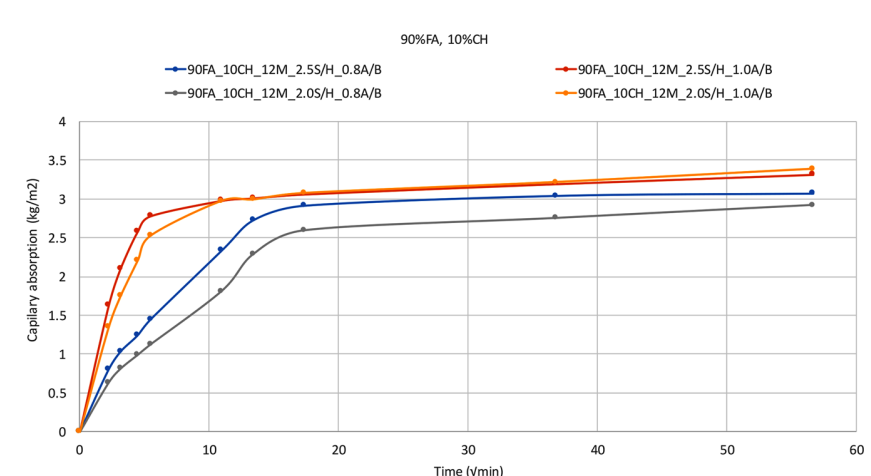

(a)

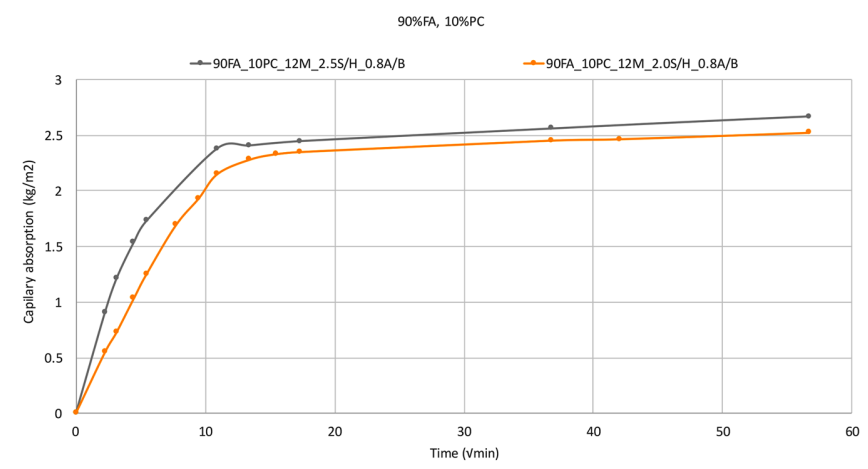

(b)

Fig. 5. Capillary Water Absorption with Time: (a) $90 \% \mathrm{FA}, 10 \% \mathrm{CH}$, (b) $90 \% \mathrm{FA}, 10 \% \mathrm{PC}$

Table 3. Modulus of Elasticity

\begin{tabular}{c|c}
\hline Formulation & Modulus of elasticity (GPa) \\
\hline 90FA_10CH_12M_2.5S/H_0.8A/B & 15.02 \\
\hline 90FA_10PC_12M_2.5S/H_0.8A/B & 12.28 \\
\hline 90FA_10PC_12M_2.0S/H_0.8A/B & 11.4 \\
\hline 90FA_10CH_12M_2.0S/H_0.8A/B & 8.8 \\
\hline 90FA_10CH_12M_2.5S/H_1.0A/B & 4.6 \\
\hline 90FA_10CH_12M_2.0S/H_1.0A/B & 3.8 \\
\hline
\end{tabular}

related mixtures show a minor reduction of the modulus of elasticity when $\mathrm{CH}$ is used instead. This because such replacement is associated to a higher content of CSH (Pangdaeng et al., 2014). AACB mixtures with a higher activator/binder ratio are associated with the lower modulus of elasticity (from 3.8 to 4.6 GPa). In this mixtures it is the increase of the sodium silicate/ sodium hydroxide ratio that explains the increase in the modulus of elasticity. An increase of the modulus of elasticity with the increase of the Si was noticed by other authors that study alkaliactivated based binders (Duxson et al., 2005). These authors suggested that the greater lability of silicate species within the sodium silicate solution allows extensive gel reorganization and densification resulting in a microstructure comprising dense gel particles. The increase of the gel volume allows for a greater cross-section of gel to support mechanical loads explaining the increase of the modulus of elasticity.

\subsection{Unrestrained Shrinkage}

Unrestrained shrinkage results are shown in Fig. 6. The

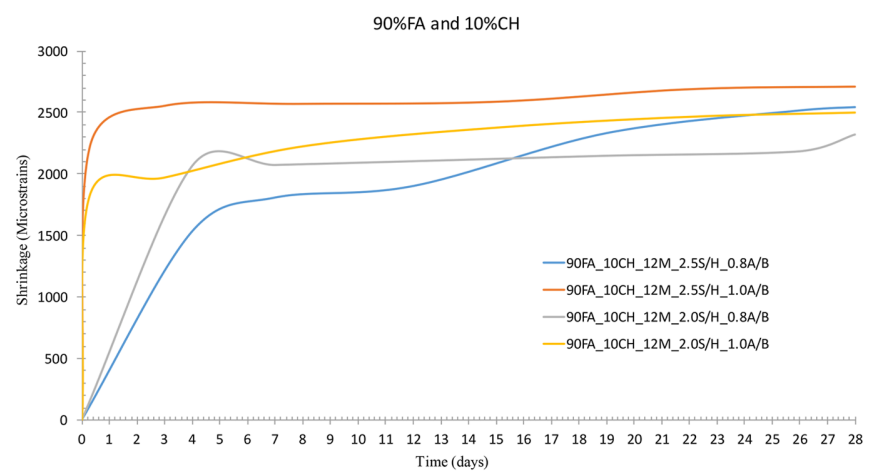

(a)

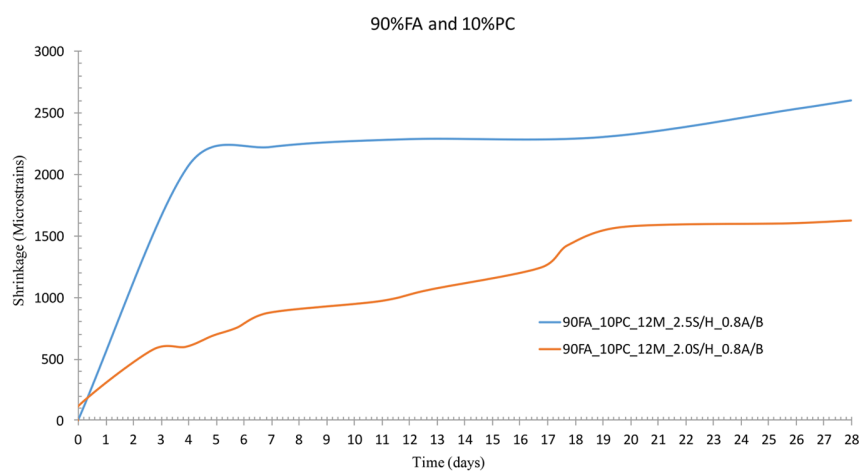

(b)

Fig. 6. Shrinkage of AACB Mortars with: (a) $90 \% \mathrm{FA}$ and $10 \% \mathrm{CH}$, (b) $90 \% \mathrm{FA}$ and $10 \% \mathrm{PC}$

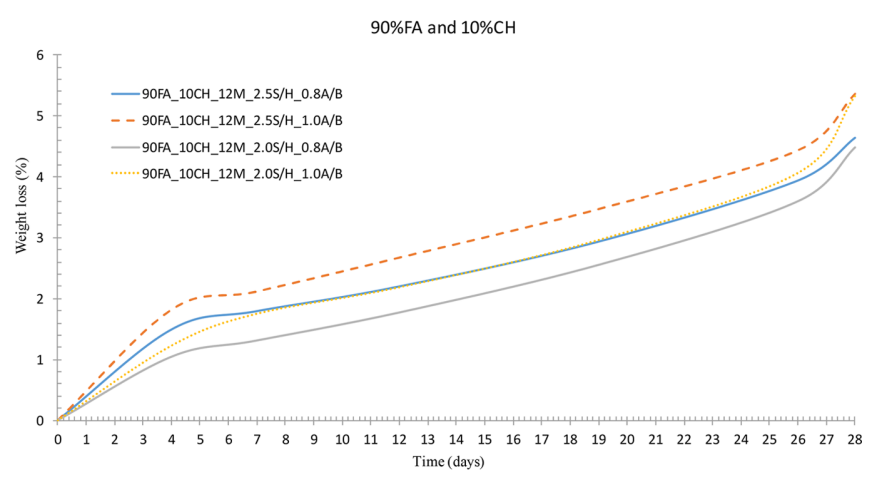

(a)

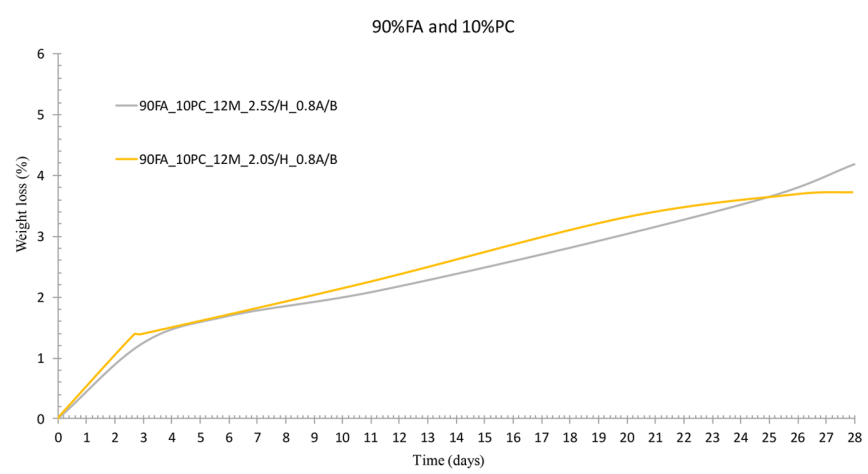

(b)

Fig. 7. Weight Loss for AACB Mortars Cured at Control Environment Temperature of $20^{\circ} \mathrm{C} \pm 3^{\circ} \mathrm{C}$ with R.H of $70 \% \pm 10 \%$ : (a) $90 \% \mathrm{FA}$ and $10 \% \mathrm{CH}$, (b) $90 \% \mathrm{FA}$ and $10 \% \mathrm{PC}$ 


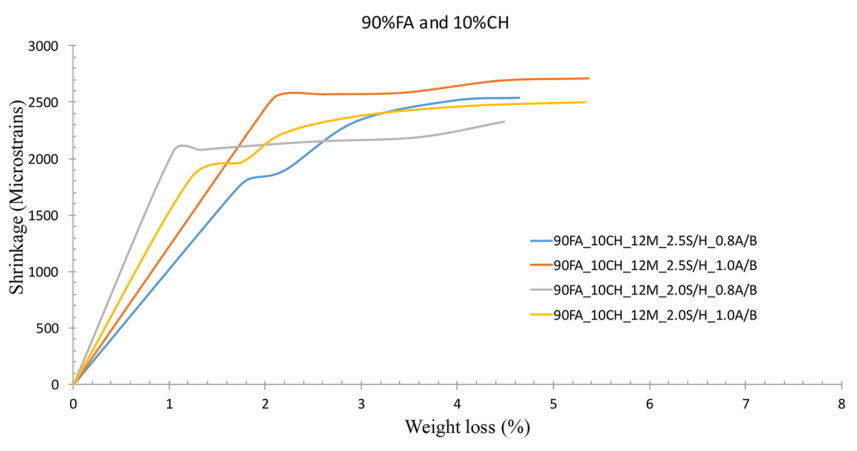

(a)

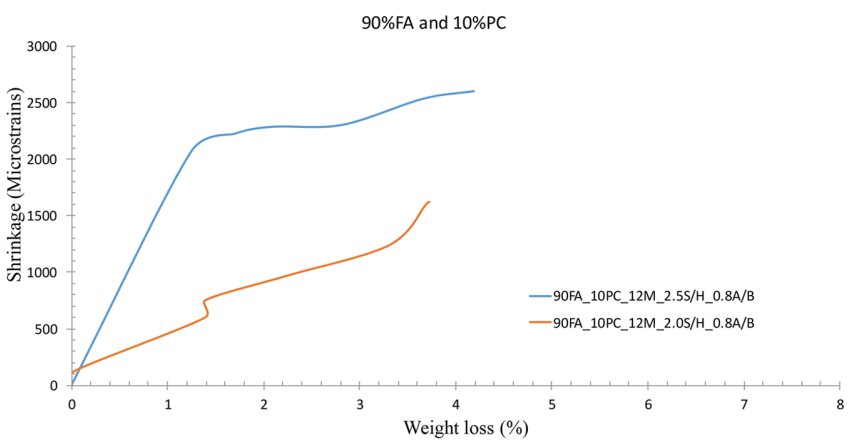

(b)

Fig. 8. Weight Loss as a Function of the Unrestrained Shrinkage for AACB Mortars: (a) $90 \% \mathrm{FA}, 10 \% \mathrm{CH}$, (b) $90 \% \mathrm{FA}, 10 \% \mathrm{PC}$

unrestrained shrinkage values exceed 1500 microstrain and can go as high as 2500 microstrain. The results of unrestrained shrinkage agree with the capillary water absorption just because the finer the capillary network the higher the capillary stress that generates shrinkage (Mobili et al., 2016). A reduction of sodium silicate is associated with a lower shrinkage as already reported by other authors (Gao et al., 2016). Fig. 7 shows the weight loss of mixtures tested for unrestrained shrinkage. The percentage weight loss was monitored, bound to be less than $6 \%$ operating 28 days of curing for all the mixtures. The mixtures with higher $\mathrm{SS} / \mathrm{SH}$ ratio show higher weight loss. Results show that mixtures with $\mathrm{CH}, \mathrm{SS} / \mathrm{SH}=2.5$ and $\mathrm{A} / \mathrm{B}=1.0$ had shown the highest weight loss while, the ones with $\mathrm{CH}, \mathrm{SS} / \mathrm{SH}=2.0$ and $\mathrm{A} / \mathrm{B}=0.8$ was the lowest, as expected. Fig. 8 shows restrained shrinkage versus the weight loss. The results show that two phases can be seen. A first one in which weight loss is proportional to unrestrained shrinkage that occurs for a weight loss below $1.5 \%$ (for mixtures with PC) and with $\mathrm{CH}$ and a lower sodium silicate content or below $2 \%$ for most mixtures with $\mathrm{CH}$ and a higher sodium silicate content. In this phase for the same weight loss of let's say $1 \%$ the lower unrestrained shrinkage is noticed for mixture 90FA_10CH_12M_2.5S/H_0.8A/B while the higher was reported for mixture 90FA_10CH_12M_2.0S/H_0.8A/B. A second phase is associated to a high water loss with minimal increase in unrestrained shrinkage. Meaning that the majority of water loss by evaporation has little influence on unrestrained shrinkage.

\subsection{Restrained Shrinkage}

\subsubsection{Crack Initiation and Propagation}

Figure 9 shows crack evolution for the mixture 90FA_10CH 12M_2.5S/H_0.8A/B. The first crack appeared after $32 \mathrm{hr}$ has propagated through the mortar ring wall (see Fig. 9(a), (b), while at the 14 days of testing (time $=336 \mathrm{hr}$ ) the crack was totally separated. For mixture 90FA_10PC_12M 2.5S/H_0.8A/B (Fig. $10)$, the initial crack was noticed after 48 hours. Fig. 11 shows the crack positions of mixture 90FA_10CH_12M_2.5S/H_1.0A/ B. As observed, crack originally initiated at mark I along the

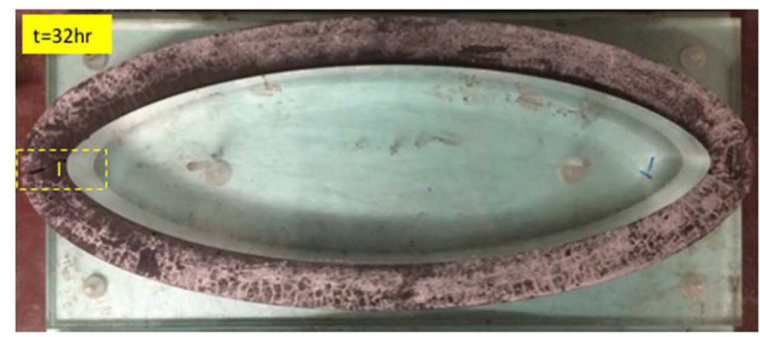

(a)

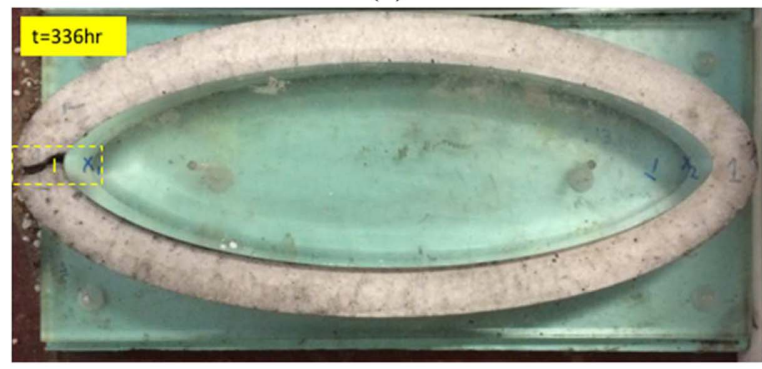

(c)

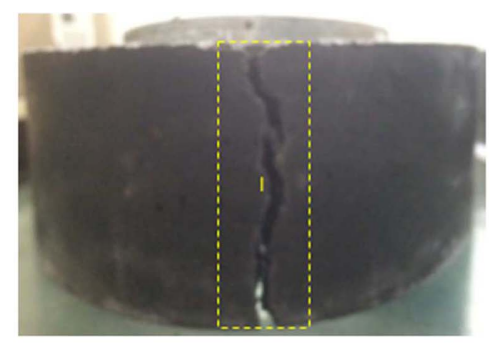

(b)

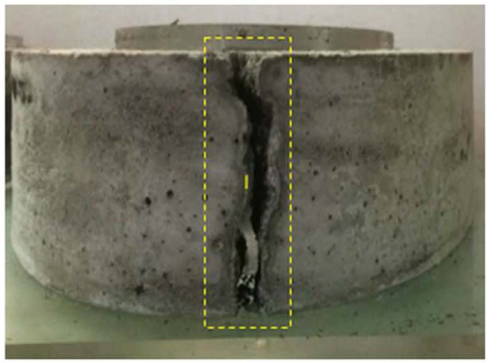

(d)

Fig. 9. Crack Positions in thin Elliptical Ring for the Mixture 90FA_10CH_12M_2.5S/H_0.8A/B: (a) Top View of the Crack Position at the Initial Time of Crack Appearance, (b) Lateral View of the Initial Crack Position, (c) Top View of the Crack Position at the Final Time of Test, (b) Lateral View of the Final Crack Position 


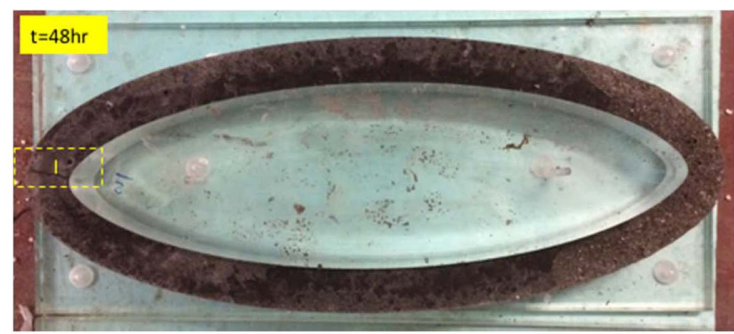

(a)

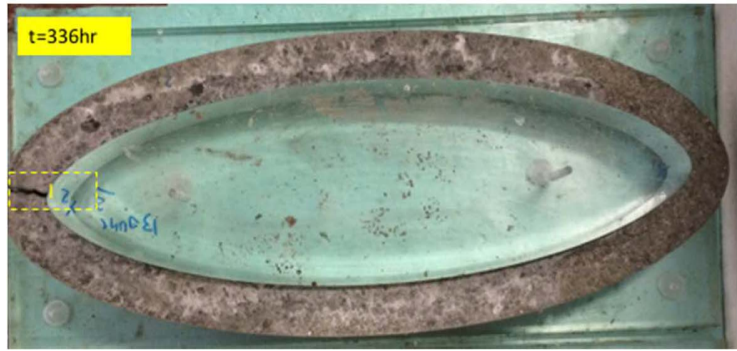

(c)

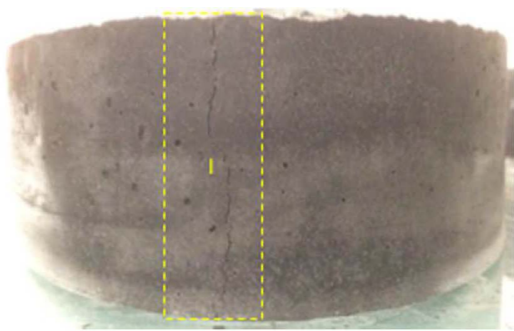

(b)

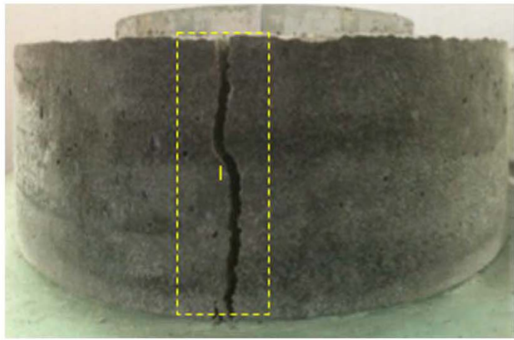

(d)

Fig. 10. Crack Positions in thin Elliptical Ring for Mixture 90FA_10PC_12M_2.5S/H_0.8A/B: (a) Top View of the Crack Position at the Initial Time of Crack Appearance, (b) Lateral View of the Initial Crack Position, (c) Top View of the Crack Position at the Final Time of Test, (b) Lateral View of the Final Crack Position

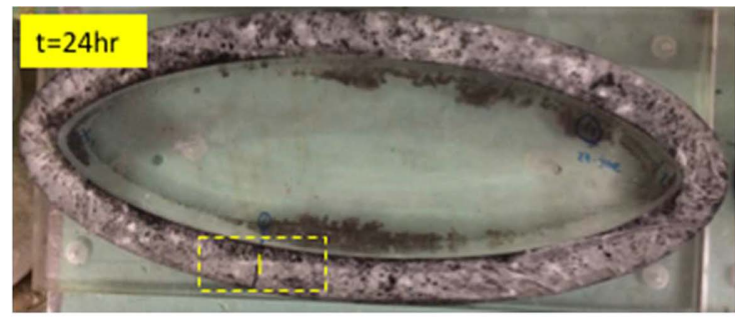

(a)

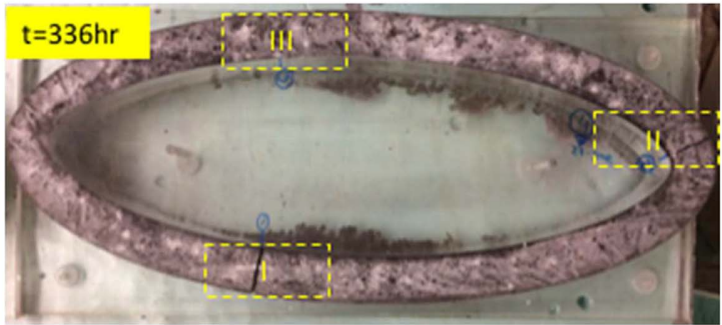

(c)

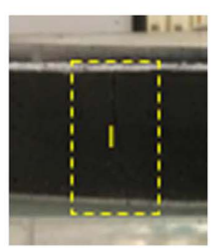

(b)
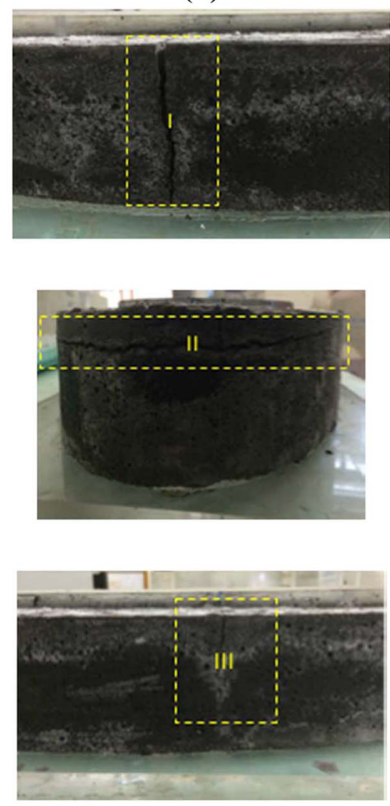

(d)

Fig. 11. Crack Positions in Thin Elliptical Ring for Mixture 90FA 10CH_12M_2.5S/H_1.0A/B: (a) Top View of the Crack Position at the Initial Time of Crack Appearance, (b) Lateral View of the Initial Crack Position, (c) Top View of the Crack Positions at the Final Time of Test, (b) Lateral View of the Final Crack Positions Composes of Three Different Crack Placement 


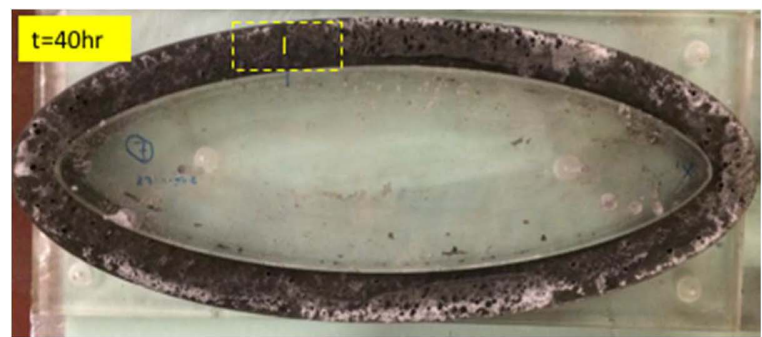

(a)

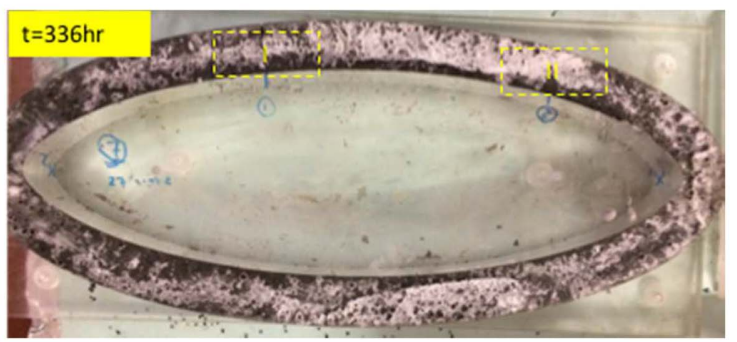

(c)

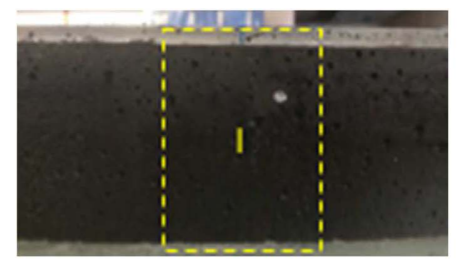

(b)
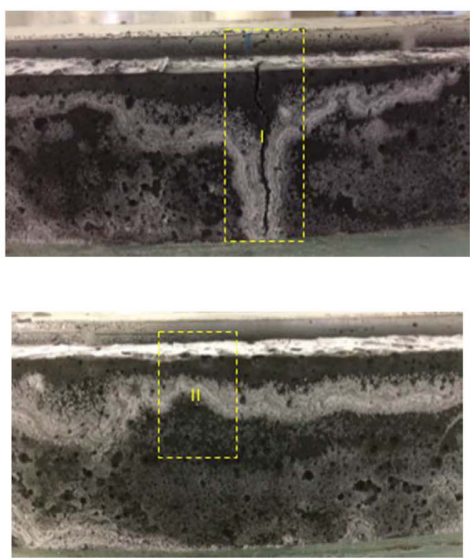

(d)

Fig. 12. Crack Positions in Thin Elliptical Ring for Mixture 90FA_10CH_12M_2.0S/H_0.8A/B: (a) Top View of the Crack Position at the Initial Time of Crack Appearance, (b) Lateral View of the Initial Crack Position, (c) Top View of the Crack Positions at the Final Time of Test, (b) Lateral View of the Final Crack Positions Composes of Two Different Positions

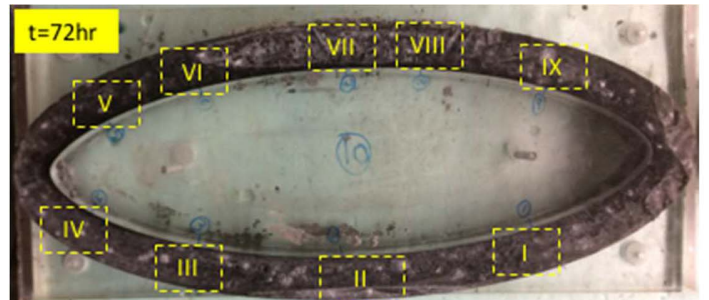

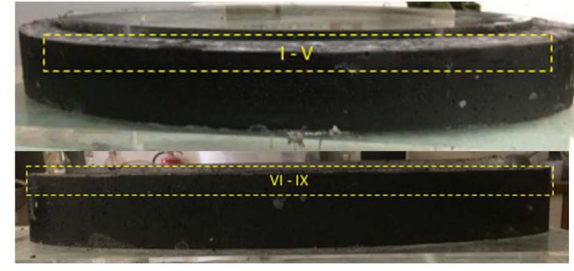

(a)

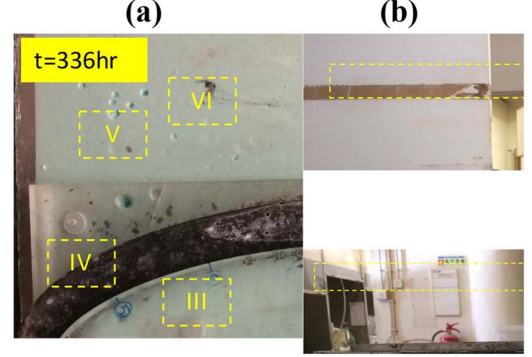

(c)

(d)

Fig. 13. Crack Positions in thin Elliptical Ring for Mixture 90FA_10CH_12M_2.0S/H_1.0A/B: (a) Top View of the Crack Position at the Initial Time of Crack Appearance, (b) Lateral View of the Initial Crack Position, (c) Top View of the Crack Position at the Final Time of Test, (b) Lateral View of the Final Crack Position Placed at Both Longitudinal Sides of the Elliptical Mortar Ring

height wall at the time of $24 \mathrm{hr}$. Then, the cracks marked as II and III were appeared but crack III ceased to propagate due to reduced crack driving energy. However, as a result of the increased tensile stress redistribution, cracks were propagated at mark I and II. However, as a result of the increased stress in mark II, it is developed in the radial direction of the ring possibly it is due to the presence of moisture gradient (Hossain and Weiss, 2004). Fig. 12 indicates that for mixture 90FA_10CH_12M_2.0S/H_0.8A/
B the initial crack was observed at $\mathrm{t}=40 \mathrm{hr}$ at the region marked as I. Crack originally initiated at mark I along the height axis due to the stress concentration which caused the appearance of another crack at mark II.. The experimental ellipse ring testing for mixture 90FA_10CH_12M_2.0S/H_1.0A/B (Fig. 13) show crack patterns different than earlier studied mortars. Initial cracks were observed after 72 hours (later than the other AACB mortars) at mark I up to IX. All the cracks shown in Fig. 13 were 

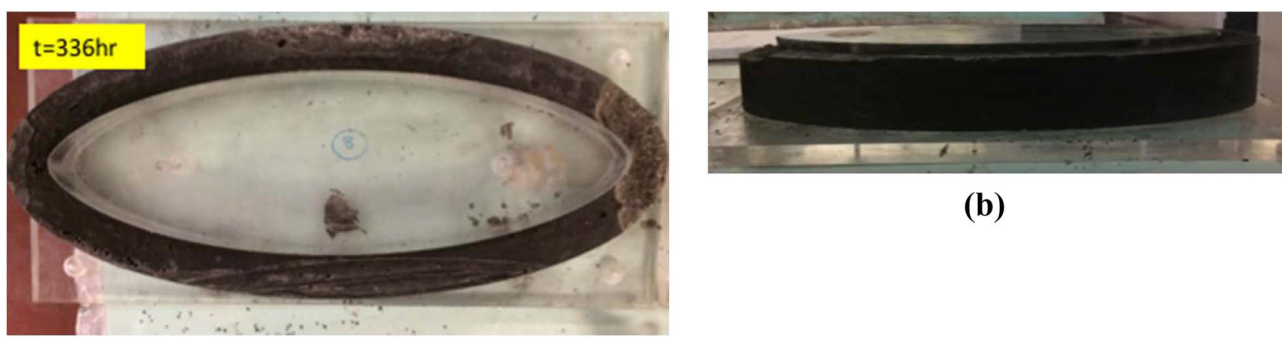

(b)

(a)

Fig. 14. No Visible Crack in thin Elliptical Ring for Mixture 90FA_10PC_12M_2.0S/H_0.8A/B at the Final Time of Test: (a) Top View, (b) Lateral View

Table 4. Visible Initial Cracking Time of the AACB Mortars

\begin{tabular}{c|c}
\hline Sample name & $\begin{array}{c}\text { Visible initial cracking } \\
\text { time (hr) }\end{array}$ \\
\hline 90FA_10CH_12M_2.5S/H_0.8A/B & 32 \\
\hline 90FA_10PC_12M_2.5S/H_0.8A/B & 48 \\
\hline 90FA_10CH_12M_2.5S/H_1.0A/B & 24 \\
\hline 90FA_10CH_12M_2.0S/H_0.8A/B & 40 \\
\hline 90FA_10PC_12M_2.0S/H_0.8A/B & $*$ \\
\hline 90FA_10CH_12M_2.0S/H_1.0A/B & 72 \\
\hline TOSD &
\end{tabular}

*No visible crack has been monitored.

observed at top surfaces with almost similar sized initial crack. This may imply that the crack driving energy was lower for this mixture having required a higher tensile stress to lead a crack to propagate after it is initiated. As shown in Fig. 14, no visible cracks were observed on the surface of the mixture 90FA $10 \mathrm{PC} 12 \mathrm{M} 2.0 \mathrm{~S} / \mathrm{H} \quad 0.8 \mathrm{~A} / \mathrm{B}$ after $336 \mathrm{hr}$ of testing. This result is related to a low modulus of elasticity as suggested by others (Ma and Ye, 2015; Mobili et al., 2016).

\subsubsection{Initial Cracking Time}

The initial cracking time is given in Table 4. It is clear that the influence of the different binder on the initial cracking time. In fact, the crack appearance of AACB mortars was strongly affected by the $\mathrm{SS} / \mathrm{SH}$ and $\mathrm{A} / \mathrm{B}$ ratios. For the ratio of $\mathrm{A} / \mathrm{B}=0.8$, the initial cracking time of mortars with $\mathrm{PC}$ apparently increased with increasing SS/SH ratio. Especially, no crack appeared for a period of $336 \mathrm{hr}$ on the mortar with $\mathrm{PC}$ with $\mathrm{SS} / \mathrm{SH}=2.0$. The initial cracking time of mortars with $\mathrm{CH}$ enhanced with decreasing ratio from $\mathrm{SS} / \mathrm{SH}=2.5$ to $\mathrm{SS} / \mathrm{SH}=2.0$ regardless of $\mathrm{A} / \mathrm{B}$ ratio. Mixtures with a high sodium silicate content, $\mathrm{A} / \mathrm{B}=$ 0.8 and PC shown an initial cracking time enhanced by $16 \mathrm{hr}$ when compared with the mortar with $\mathrm{CH}$. It seems that PC inclusion decreased the cracking sensitivity. It is further noticed that for mixture 90FA_10CH_12M_2.0S/H_1.0A/B, the initial crack was visible much later than that of $\mathrm{CH}$ mortar with the similar ratios of $\mathrm{SS} / \mathrm{SH}$ or $\mathrm{A} / \mathrm{B}$.

\subsubsection{Crack Width}

The average value of the crack width is presented in Fig. 15. It can be seen that in all cases (except for mixture 90FA_10PC

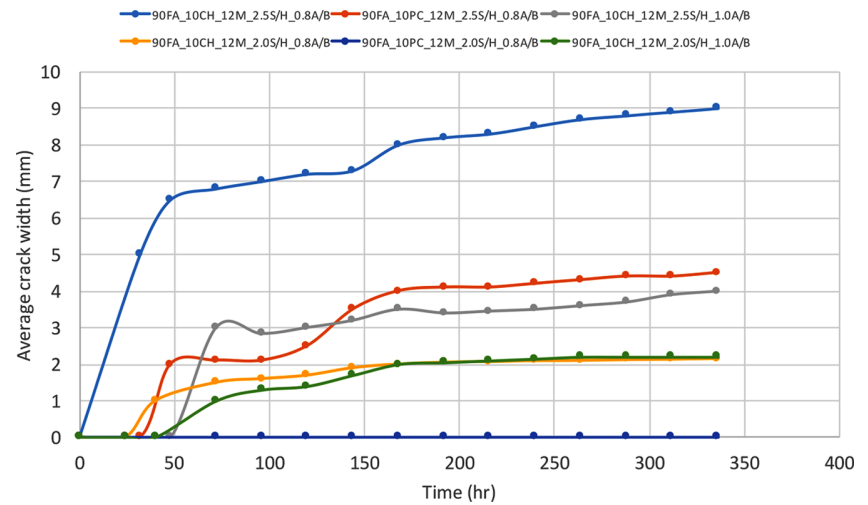

Fig. 15. Average Crack Width for Different Mortars During Tested Period of 14 days

12M_2.0S/H_0.8A/B), a gradual increase with age followed by a sudden and significant jump in the width of the cracks. As specimen dries, its shrinkage increases with age. However, enhancing shrinkage of the material is restrained by the central ellipse ring; resulting in an increase of the tensile stress which is imposed on the central ellipse ring. Simultaneously, tensile stress is developed in the mortar. When the tensile stress exceeds the tensile strength of mortar, crack initiates and the stress imposed by central ring is released. Comparing the crack width of mixture containing $\mathrm{CH}$, a maximum crack width was noticed for a higher sodium silicate content and $\mathrm{A} / \mathrm{B}=0.8$. The increase in the activator/binder ratio lead to a $55 \%$ reduction of the width crack at 14 days of testing. It is also noticed, for the ratio $\mathrm{A} / \mathrm{B}=0.8$, that increasing sodium silicate content increase the average crack width by approximately $4.5 \mathrm{~mm}$. The reduction of sodium silicate content delays the appearance of cracks and is also associated to lower crack width. Results also show that higher unrestrained shrinkage is associated with higher crack width.

\subsection{Relationship between Unrestrained Shrinkage and Restrained Shrinkage}

Figure 16 shows the relationship between average crack width (mm) and length change (microstrain) for different studied mortars. For most mixtures no clear correlation exists between the two parameters. However, for mixture 90FA_10PC_12M $2.5 \mathrm{~S} / \mathrm{H} \_0.8 \mathrm{~A} / \mathrm{B}$ a clear correlation was detected. This mixture has not only a high sodium silicate/sodium hydroxide ratio but 


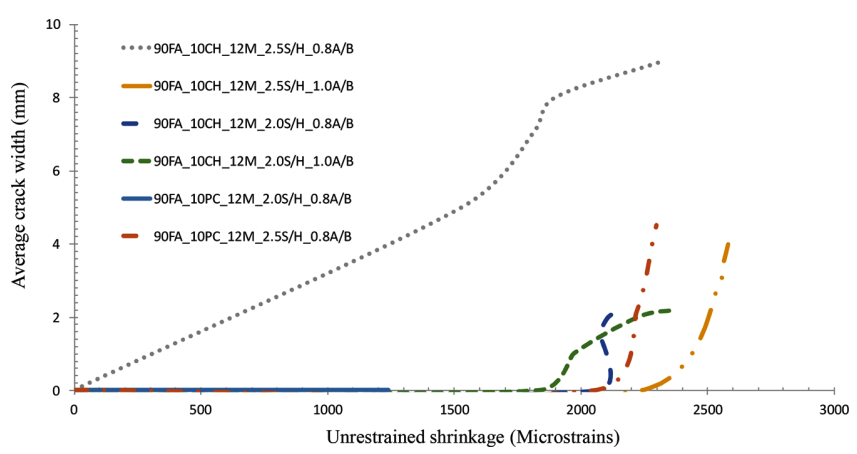

Fig. 16. Relationship between Average Crack width and Unrestrained Shrinkage

also a reduced activator/binder ratio the variables that are prone to the worst performance concerning the use of AACB mortars for restrained conditions. This means that for such conditions the use of fibres maybe needed to prevent crack appearance.

\section{Conclusions}

Some authors reported that alkali-activated cement based binder (AACB) mortars can have much higher drying shrinkage than Portland cement based composites. Its worth remember that shrinkage performance is a very important property for reinforced concrete composites just because a high shrinkage performance is associated to cracking tendency that leads to future durability problems. This paper provides results on restrained and unrestrained shrinkage performance of fly ash AACB mortars. The restrained shrinkage was assessed with the use of an elliptical ring. This device provides a faster and more reliable assessment of cracking potential than circular rings. Based on results of the testing program the following conclusions can be made. Mixtures with lower sodium silicate content are associated to lower unrestrained shrinkage. Weight loss results show that the majority of water loss by evaporation has little influence on unrestrained shrinkage. Elliptical ring tests revealed, that most of the crack initiated at the vertices on the axis and propagated from the top surface to the outer of the wall. Mixtures with $\mathrm{CH}$ and lower SS/SH ratio exhibited an older visible initial cracking time. While, in the specimens with $\mathrm{PC}$ at lower $\mathrm{SS} / \mathrm{SH}$ ratio did not cause any visible crack during 14 days of testing. Results show that higher unrestrained shrinkage is associated with higher crack width. The reduction of the activator/binder ratio is associated to higher modulus of elasticity and higher restrained shrinkage. The reduction of sodium silicate content delays the appearance of cracks and is also associated to lower crack width. The use of AACB mortars in restrained conditions requires the use of a reduced sodium silicate content or else the use of fibres to prevent crack appearance.

\section{Acknowledgements}

The authors would like to acknowledge the financial support of the Foundation for Science and Technology (FCT) in the frame of project IF/00706/2014-UM.2.15

\section{References}

American Coal Ash Association (2016). https://www.acaa-usa.org/ Publications/ Production-Use-Reports.

ASTM (2000). Standard Practice for Use of Apparatus for the Determination of Length Change of Hardened Cement Paste, Mortar, and Concrete, ASTM International, West Conshohocken, PA, www.astm.org.

ASTM C618 - 15 (2015). Standard Specification for Coal Fly Ash and Raw or Calcined Natural Pozzolan for Use in Concrete, ASTM International, West Conshohocken, PA, www.astm.org.

Bernal, S., Rodríguez, E., Kirchheim, A., and Provis, J. (2016) "Management and valorisation of wastes through use in producing alkali-activated. Cement materials." Journal of Chemical Technology \& Biotechnology (in press), DOI: $10.1002 /$ jctb.4927.

Beushausen, H. and Chilwesa, M. (2013). "Assessment and prediction of drying shrinkage in bonded mortar overlays." Cement and Concrete Research, Vol. 53, pp. 256-266, DOI: 10.1016/j.cemconres.2013.07.008.

Borges, P. H. R., Banthia, N., Alcamand, H., Vasconcelos, W., and Nunes, E. H. M. (2016). "Performance of blended metakaolin/blastfurnace slag alkali-activated mortars." Cement and Concrete Composites, Vol. 71, pp. 42-52, DOI: 10.1016/j.cemconcomp.2016. 04.008.

Chindaprasirt, P. and Cao, T. (2014). "Reuse of recycled aggregate in the production of alkali-activated concrete." In Handbook of Alkali-Activated Cements, Mortars and Concretes, 519-538 (Eds) Pacheco-Torgal, F., Labrincha, J., Palomo, A., Leonelli, C., Chindaprasirt, P., WoddHead Publishing, Cambridge, UK, DOI: 10.1533/9781782422884.4.519.

Collins, F. and Sanjayan, J. G. (1999). "Workability and mechanical properties of alkali-activated slag concrete." Cem. Concr. Res., Vol. 29, pp. 455-458, DOI: 10.1016/S0008-8846(98)00236-1.

Collins, F. and Sanjayan, J. G. (2000). "Cracking tendency of alkaliactivated slag concrete subjected to restrained shrinkage." Cem. Concr. Res., Vol. 30, No. 5, pp. 791-798, DOI: 10.1016/S00088846(00)00243-X.

Collins, F. and Sanjayan, J. G. (2000). "Effect of pore size distribution on drying shrinkage of alkali-activated slag concrete." Cem. Concr. Res., Vol. 30, No. 9, pp. 1401-1406, DOI: 10.1016/S0008-8846(00) 00327-6.

COM (2014). 398 final. Towards a circular economy: A zero waste programme for Europe, Communication from the Commission to the European Parliament, the Council, the European Economic and Social Committee and the Committee of the Regions. Brussels, 2.7.2014.

Dong, W., Zhou, X., and Wu, Z. (2014). "A fracture mechanics-based method for prediction of cracking of circular and elliptical concrete rings under restrained shrinkage." Engineering Fracture Mechanics, Vol. 131, pp. 687-701, DOI: 10.1016/j.engfracmech.2014.10. 015.

Dong, W., Zhou, X., Wu, Z., and Kastiukas, G. (2016). "Effects of specimen size on assessment of shrinkage cracking of concrete via elliptical rings: Thin vs thick." Computers and Structures, Vol. 174, pp. 6678, DOI: 10.1016/j.compstruc.2015.12.005.

Duxon, P., Provis, J., Grant, Lukey., Mallicoat, Seth., Kriven, Waltraud, and Deventer, Jannie (2005). "Understanding the relationship between geopolymer composition, microstructure and mechanical properties." Colloids and Surfaces, Vol. 269, pp. 47-58.

EN (2002). 1015-18: Methods of test for mortar for masonry, Determination of water absorption coefficient due to capillary action of hardened 
mortar, European Committee for Standardization, Brussels.

European standar prEN 12390-13 (2013). Testing hardened concrete Part 13: Determination of secant modulus of elasticity in compression, Brussels.

Gao, X., Yu, Q., and Brouwers, H. (2016). “Assessing the porosity and shrinkage of alkali activated slag-fly ash composites designed applying a packing model." Construction and Building Materials, Vol. 119, pp. 175-184, DOI: 10.1016/j.conbuildmat.2016.05.026.

Hossain, A. and Weiss, J. (2004). "Assessing residual stress development and stress relaxation in restrained concrete ring specimens." Cement and Concrete Composites, Vol. 26, No. 5, pp. 531-540, DOI: 10.1016/S0958-9465(03)00069-6.

Khan, M. (2013). "Ring test for the measurement of restrained shrinkage of concrete." Applied Mechanics and Materials, Vol. 377, pp. 86-91, 10.4028/www.scientific.net/AMM. 377.86.

Kristiawan, S. (2012). "Evaluation of models for estimating shrinkage stress in patch repair system." International Journal of Concrete Structures and Materials, Vol. 6, No. 4, pp. 221230, DOI: 10.1007/s40069-012-0023-y.

Lee, N., Jang, J., and Lee, H. (2014). "Shrinkage characteristics of alkali-activated fly ash/slag paste and mortar at early ages." Cem. Concr. Compos., Vol. 53, pp. 239-248, DOI: 10.1016/j.cemconcomp. 2014.07.007.

Ma, Y. and Ye, G. (2015). "The shrinkage of alkali activated fly ash." Cement and Concrete Research, Vol. 68, pp. 75-82, DOI: 10.1016/ j.cemconres.2014.10.024.

Mobili, A., Belli, A., Giosué, C., Bellezze, T., and Tittarelli, F. (2016). "Metakaolin and fly ash alkali-activated mortars compared with cementitious mortars at the same strength class." Cement and Concrete Research, Vol. 88, pp. 198-210, DOI: 10.1016/j.cemconres. 2016.07.004.

Pacheco-Torgal, F. (2014). Introduction. In Handbook of Alkali-Activated Cements, Mortars and Concretes, 1-16 (Eds) Pacheco-Torgal, F., Labrincha, J., Palomo, A., Leonelli, C., Chindaprasirt, P., WoddHead Publishing, Cambridge, UK, DOI: 10.1533/9781782422884.1.

Pacheco-Torgal, F., Castro-Gomes, J., and Jalali, S. (2008). "Properties of tungsten mine waste geopolymeric binder." Construction and Building Materials, Vol. 22, pp. 1201-1211, DOI: 10.1016/j.conbuildmat. 2007.01.022.
Pangdaeng, S., Phoo-ngernkham, T., Sata, V., and Chindaprasirt, P. (2014). "Influence of curing condition on the properties of high calcium fly ash geopolymer containing Portland cement as additive." Materials \& Design, 2014, Vol. 53, pp. 269-274, DOI: 10.1016/j.matdes.2013. 07.018.

Payá, J., Monzó, J., Borrachero, M. V., and Tashima, M. M. (2014). "Reuse of aluminosilicate industrial waste materials in the production of alkali-activated concrete binders." In Handbook of Alkali-Activated Cements, Mortars and Concretes, 487-518 (Eds) Pacheco-Torgal, F., Labrincha, J., Palomo, A., Leonelli, C., Chindaprasirt, P., WoddHead Publishing, Cambridge, UK, DOI: 10.1533/9781782422884.4.487.

Pinto, A. T. (2004). Metakaolin alkali-activated based binders, PhD thesis, University of Minho, Portugal.

Provis, J. L. (2014). "Geopolymers and other alkali activated materials: Why, how, and what?." Materials and Structures, Vol. 47, pp. 11-25, DOI: 10.1617/s11527-013-0211-5.

van Deventer, J. S. J., Provis, J. L., and Duxson, P. (2012). "Technical and commercial progress in the adoption of geopolymer cement." Minerals Eng, Vol. 29, pp. 89-104, 10.1016/j.mineng.2011. 09.009.

Van Deventer, J., Provis, J., Duxson, P., and Brice, D. (2010). “Chemical research and climate change as drivers in the commercial adoption of alkali activated materials." Waste Biomass Valor, Vol. 1, pp. 145155, DOI: 10.1007/s12649-010-9015-9.

Wallah, S. and Hardjito, D. (2014). "Assessing the shrinkage and creep of alkali-activated concrete binders. In Handbook of Alkali-Activated Cements, Mortars and Concretes, 265-290 (Eds) Pacheco-Torgal, F., Labrincha, J., Palomo, A., Leonelli, C., Chindaprasirt, P., WoddHead Publishing, Cambridge, UK, DOI: 10.1533/9781782422884.2.265.

Ye, H. and Radlinska, A. (2016). "Shrinkage mechanisms of alkaliactivated slag." Cement and Concrete Research, Vol. 88, pp. 126135, DOI: 10.1016/j.cemconres.2016.07.001.

Zhou, X., Dong, W., and Oladiran, O. (2014). “Assessment of restrained shrinkage cracking of concrete using elliptical ring specimens: experimental and numerical." ASCE J. Mater Civ Engng, DOI: 10.1061/(ASCE) MT. 1943-5533.000100.

Zhuang, X.-Y., Chen, L., Komarneni, S., Zhou, C.-H., Tong, D.-S., Yang, H.-M., Yu, W.-H., and Wang, H. (2016). "Fly ash-based geopolymer: Clean production, properties and applications." Journal of Cleaner Production, Vol. 125, pp. 253-267, DOI: 10.1016/j.jclepro. 2016.03.019. 